\title{
Weak Calcium-Mediated Interactions between Lewis X-Related Trisaccharides Studied by NMR Measurements of Residual Dipolar Couplings
}

\author{
Gabrielle Nodet, Luisa Poggi, Daniel Abergel, ${ }^{*}$ Chafika Gourmala, Dengxiang Dong, \\ Yongmin Zhang, Jean-Maurice Mallet, and Geoffrey Bodenhausen \\ Contribution from the Département de Chimie, associé au CNRS, Ecole Normale Supérieure, 24, \\ rue Lhomond, 75231 Paris Cedex 05, France
}

Received February 15, 2007; E-mail: daniel.abergel@ens.fr

\begin{abstract}
The Lewis $\mathrm{X}\left(\mathrm{Le}^{\mathrm{X}}\right)$ determinant, a trisaccharide with the carbohydrate sequence $\operatorname{Gal} \beta(1 \rightarrow 4)$ $[$ Fuc $\alpha(1 \rightarrow 3)] \mathrm{GlcNAc} \beta$, is believed to be responsible for $\mathrm{Ca}^{2+}$-mediated cell-cell interactions. In partly oriented phases composed of mixtures of penta(ethyleneglycol)monododecyl ether $\mathrm{HO}\left(\mathrm{CH}_{2} \mathrm{CH}_{2} \mathrm{O}\right)_{5} \mathrm{C}_{12} \mathrm{H}_{25}$ and $n$-hexanol in the presence of $\mathrm{Ca}^{2+}$ ions, the variation of the residual dipolar couplings ${ }^{1} D_{\mathrm{CH}}$ of various $\mathrm{C}_{i} \mathrm{H}_{i}$ vectors in $\mathrm{Le}^{\mathrm{X}}$ as a function of the concentration of the trisaccharide demonstrates the existence of very weak $\mathrm{Le}^{\mathrm{X}}-\mathrm{Ca}^{2+}-\mathrm{Le}^{\mathrm{x}}$ complexes in solution. Synthetic 3-, 4-, and 6-deoxy-Le $\mathrm{C}^{\mathrm{X}}$ variants were also shown to form complexes in the presence of calcium ions, despite the replacement of one of their hydroxyl groups by hydrogen atoms. This is the first direct observation in solution of a calcium-mediated interaction between Lex molecules.
\end{abstract}

\section{Introduction}

Primary structures of proteins and nucleic acids may be regarded as textual messages where individual building blocks, i.e., the amino acids or nucleotides, may be compared to letters of the alphabet. By comparison, the syntax of carbohydrates is much more sophisticated, since multiple linkages can lead to branched structures. ${ }^{1,2}$ An illustration of the resulting complexity is provided by the glycoconjugate coating of the outer membranes of most cells. This coating is involved in interactions with the extracellular environment and is partly responsible for cell-cell communications. ${ }^{3}$ In a seminal work, ${ }^{4}$ Hakomori proposed that carbohydrate-carbohydrate interactions ${ }^{5-7}$ may be responsible for the initial step of cell adhesion. One of the structures involved in this mechanism is the Lewis $\mathrm{X}\left(\mathrm{Le}^{\mathrm{X}}\right)$ determinant, a trisaccharide unit with the carbohydrate sequence $\operatorname{Gal} \beta(1 \rightarrow 4)[$ Fuc $\alpha(1 \rightarrow 3)]$ GlcNAc $\beta$ (Figure 1).

Two $\mathrm{Le}^{\mathrm{X}}$ determinant units can interact to form a $\mathrm{Le}^{\mathrm{X}}-\mathrm{Ca}^{2+}-$ $\mathrm{Le}^{\mathrm{X}}$ complex in the presence of divalent $\mathrm{Ca}^{2+}$ cations, ${ }^{9,10}$ as

(1) Gabius, H. J. Naturwissenschaften 2000, 87, 108-121.

(2) Dwek, R. A. Chem. Rev. 1996, 96, 683-720.

(3) Gabius, H. J.; Siebert, H. C.; Andre, S. ; Jimenez-Barbero, J.; Rüdiger, H ChemBioChem 2004, 5, 741-764.

(4) Hakomori, S. Pure Appl. Chem. 1991, 63, 473-482.

(5) Bovin, N. V. In Glycosciences, status and perspectives; Gabius, H.-J., Gabius, S., Eds.; Chapmann and Hall: Weinheim, 1997; pp 277-289. ..

(6) Carbohydrates in Chemistry and Biology; Ernst, B., Hart, G. W., Sinay, P., Eds.; Wiley-VCH: Weinheim, 2000; Vol. 2, pp 1061-1091.

(7) Rojo, J.; Morales, J. C.; Penadés, S. In Host-Guest Chemistry; Penadés, S., Ed.; Topics in Current Chemistry 218; Springer-Verlag: BerlinHeidelberg, 2002; pp 45-92.

(8) Yvelin, F.; Zhang, Y.; Mallet, J.-M.; Jeannin, Y.; Sinay, P. Carbohydr. Lett. 1996, 1, 475-482.

(9) Eggens, I.; Fenderson, B.; Toyokuni, T.; Dean, B.; Stroud, M.; Hakomori, S. J. Biol. Chem. 1989, 264, 9476-9484.

(10) Kojima, N.; Fenderson, B. A.; Stroud, M. R.; Goldberg, R. I.; Habermann, R.; Toyokuni, T.; Hakomori, S. Glycoconjugate J. 1994, 11, 238-248.

9080 — J. AM. CHEM. SOC. 2007, 129, 9080-9085

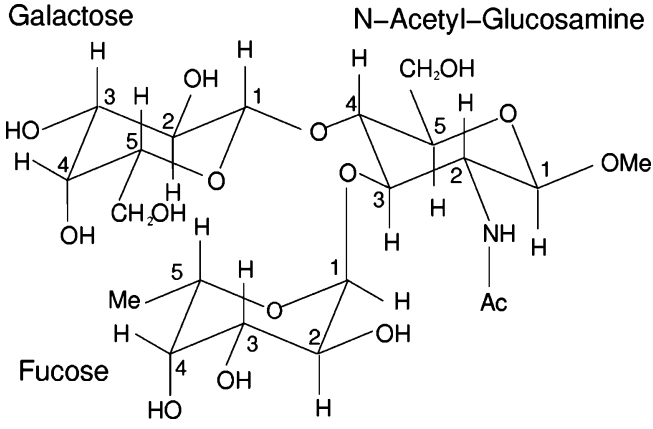

Figure 1. Structure of the methyl glycoside $\mathrm{Le}^{\mathrm{X}}$ determinant $\mathrm{Gal} \beta(1 \rightarrow 4)$ $[$ Fuc $\alpha(1 \rightarrow 3)]$ GlcNAc $\beta$ OMe. $^{8}$

demonstrated by NMR, ${ }^{11-15}$ mass spectrometry, ${ }^{16}$ vesicle adhesion, ${ }^{17,18}$ atomic force microscopy, ${ }^{19}$ surface plasmon resonance, ${ }^{20}$ and functionalized gold nanoparticles. ${ }^{21}$ Rat basophilic

(11) Wormald, M. R.; Edge, C. J.; Dwek, R.A. Biochem. Biophys. Res. Commun. 1991, 180, 1214-1221.

(12) Henry, B.; Desvaux, H.; Pristchepa, M.; Berthault, P.; Zhang, Y.; Mallet, J.-M.; Esnault, J.; Sinay, P. Carbohydr. Res. 1999, 315, 48-62.

(13) Geyer, A.; Gege, C.; Schmidt, R. R. Angew. Chem. 1999, 111, 15691571; Angew. Chem., Int. Ed. 1999, 38, 1466-1468.

(14) Geyer; A.; Gege, C.; Schmidt, R. R. Angew. Chem. 2000, 112, 33813385; Angew. Chem., Int. Ed. 2000, 39, 3246-3249.

(15) Geyer, A.; Gege, C.; Schmidt, R. R. Eur. J. Org. Chem. 2002, 15, 24752485.

(16) Siuzdak, G.; Ichikawa, Y.; Caulfield, T. J.; Munoz, B.; Wong, C.-H.; Nicolaou, K. C. J. Am. Chem. Soc. 1993, 115, 2877-2881.

(17) Pincet, F.; Le Bouar, T.; Zhang, Y.; Esnault, J.; Mallet, J.-M.; Perez, E. Sinay, P. Biophys. J. 2001, 80, 1354-1358.

(18) Gourier, C.; Pincet, F.; Perez, E.; Zhang, Y.; Mallet, J.-M.; Zhu, Z.; Sinay, P. Angew. Chem., Int. Ed. 2005, 44, 1683-1687.

(19) Tromas, C.; Rojo, J.; de la Fuente, J. M.; Barrientos, A. G.; Penadés, S Angew. Chem. 2001, 113, 3142-3141; Angew. Chem., Int. Ed. 2001, 40 $3052-3055$.

(20) Hernáiz, M. J.; de la Fuente, J. M.; Barrientos, A. G.; Penadés, S. Angew. Chem. 2002, 114, 1624-1627; Angew. Chem. Int. Ed. 2002, 41, 15541557. 
leukemia cells preincubated with purified $\mathrm{Le}^{\mathrm{X}}$ grafted on glycosphingolipids have also been used to study $\mathrm{Le}^{\mathrm{X}} / \mathrm{Le}^{\mathrm{X}}$ interactions. ${ }^{22}$ Weak interactions with $\mathrm{Ca}^{2+}$ have been detected by NMR for $\mathrm{Le}^{\mathrm{X}}$ oligosaccharides tethered to lipid bilayers, ${ }^{13}$ but $\mathrm{Ca}^{2+}$-induced complexation of $\mathrm{Le}^{\mathrm{X}}$ glycoconjugates has not been observed so far in solution. An analysis of one-bond residual dipolar couplings (RDCs), ${ }^{1} D\left({ }^{13} \mathrm{C}^{1} \mathrm{H}\right)={ }^{1} D_{\mathrm{CH}}$, in weakly aligned liquid crystalline solutions shows that the three saccharide residues of $\mathrm{Le}^{\mathrm{X}}$ adopt fairly rigid relative orientations; ${ }^{23}$ this analysis has become a standard for carbohydrates lately. ${ }^{24-26}$

In this article, we describe an experimental strategy to characterize weak $\mathrm{Le}^{\mathrm{X}} / \mathrm{Ca}^{2+} / \mathrm{Le}^{\mathrm{X}}$ interactions. Our approach relies on the measurement of ${ }^{1} D_{\mathrm{CH}}$ with carbon-13 in natural abundance in $\mathrm{Le}^{\mathrm{X}}$ dissolved in a weakly aligned liquid crystalline solution. We used modulation experiments ${ }^{27}$ rather than direct measurements of doublet splittings. In the presence of $\mathrm{Ca}^{2+}$, the variation of ${ }^{1} D_{\mathrm{CH}}$ as a function of the $\mathrm{Le}^{\mathrm{X}}$ concentration provides unequivocal evidence of the existence of $\mathrm{Le}^{\mathrm{X}}-\mathrm{Ca}^{2+}-$ $\mathrm{Le}^{\mathrm{X}}$ complexes in solution. In an effort to better understand the formation of such complexes, several synthetic variants of $\mathrm{Le}^{\mathrm{X}}$ were investigated.

\section{Experimental Methods}

Sample Preparation. In a first set of experiments, we investigated a solution of $10 \mathrm{mM} \mathrm{Le}^{\mathrm{X}}$ with ${ }^{13} \mathrm{C}$ in natural abundance, synthetized as described elsewhere, ${ }^{8}$ dissolved in a mixture of penta(ethyleneglycol)monododecyl ether $\left(\mathrm{HO}\left(\mathrm{CH}_{2} \mathrm{CH}_{2} \mathrm{O}\right)_{5} \mathrm{C}_{12} \mathrm{H}_{25}\right)$ and $n$-hexanol (henceforth denoted as $\left.\mathrm{C}_{12} \mathrm{E}_{5} / \mathrm{h}\right){ }^{28}$ The $\mathrm{C}_{12} \mathrm{E}_{5}$ concentration was about $50 \mathrm{~g} \cdot \mathrm{L}^{-1}$ in $\mathrm{D}_{2} \mathrm{O}$, with a molar ratio $\left[\mathrm{C}_{12} \mathrm{E}_{5}\right] /[$ hexanol $] \approx 0.96$. Small amounts $(2$ $\mu \mathrm{L}$ ) of a concentrated solution of $1.2 \mathrm{~mol} \cdot \mathrm{L}^{-1} \mathrm{CaCl}_{2}$ were added in order to minimize dilution effects. During the addition of $\mathrm{CaCl}_{2}$ solution, the sample was frozen by immersion of the NMR tube into a mixture of acetone/dry ice at $195 \mathrm{~K}$ to avoid evaporation of $n$-hexanol while the tube cap was removed. No background salt other than $\mathrm{CaCl}_{2}$ was added. The existence of a weakly oriented $\mathrm{C}_{12} \mathrm{E}_{5} / \mathrm{h}$ phase was indicated by a residual quadrupolar coupling of the deuterium resonance of $\mathrm{D}_{2} \mathrm{O}$, $\omega_{\mathrm{Q}} / 2 \pi=36 \mathrm{~Hz}$ at $300.0 \mathrm{~K}$ in the absence of $\mathrm{CaCl}_{2}$. This splitting remained unchanged in the presence of $23 \mathrm{mM} \mathrm{CaCl}_{2}$. Because of the viscosity of $\mathrm{C}_{12} \mathrm{E}_{5}$, the exact ratio $\left[\mathrm{C}_{12} \mathrm{E}_{5}\right] /[$ hexanol $] \approx 0.96$ was difficult to reproduce, leading to variations of $\omega_{\mathrm{Q}}$ between the various samples. One should therefore avoid comparing RDCs measured in different samples. No variations of ${ }^{1} \mathrm{H}$ and ${ }^{13} \mathrm{C}$ chemical shifts or line widths of the $\mathrm{Le}^{\mathrm{X}}$ resonances were observed upon addition of $\mathrm{CaCl}_{2}$. The $\mathrm{Le}^{\mathrm{X}}$ concentration was increased stepwise from 10 to 14 to $20 \mathrm{mM}$ by dissolving the solid saccharide directly in the NMR tube.

The $\mathrm{Le}^{\mathrm{X}}$-related trisaccharides 3-deoxygalactose-Le ${ }^{\mathrm{X}}$, 4-deoxygalactose-Le ${ }^{\mathrm{X}}$, and 6-deoxygalactose-Le $\mathrm{C}^{\mathrm{X}}$ were synthesized with ${ }^{13} \mathrm{C}$ in natural abundance. ${ }^{29,30}$ The RDCs were measured as a function of the

(21) de la Fuente, J. M.; Eaton, P.; Barrientos, A. G.; Menéndez, M.; Penadés, S. J. Am. Chem. Soc. 2005, 127, 6192-6197.

(22) Boubelík, M.; Floryk, D.; Bohata, J.; Dráberová, L.; Macák, J.; Smíd, F.; Dráber, P. Glycobiology 1998, 8, 139-146.

(23) Azurmendi, H. F.; Martin-Pastor, M.; Bush, C. A. Biopolymers 2002, 63, 89-98.

(24) Landersjo, C.; Stevensson, B.; Eklund, R.; Ostervall, J.; Soderman, P.; Widmalm, G.; Maliniak, A. J. Biomol. NMR 2006, 35, 89-101.

(25) Venable, R. M.; Delaglio, F.; Norris, S. E.; Freedberg, D. I. Carbohydr. Res. 2005, 340, 863-874.

(26) Tian, F.; Al Hashimi, H. M.; Craighead, J. L.; Prestegard, J. H. J. Am. Chem. Soc. 2001, 123, 485-492.

(27) Pham, T. N.; Liptaj, T.; Bromek, K.; Uhrín, D. J. Magn. Reson. 2002, 157, 200-209.

(28) Rückert, M.; Otting, G. J. Am. Chem. Soc. 2000, 122, 7793-7797.

(29) Gourmala, C. Ph.D. thesis, Université Denis Diderot (Paris 7), June 23, 2006.

(30) Dong, D. Ph.D. thesis, Universisté Pierre et Marie Curie (Paris 6), March $1,2006$.

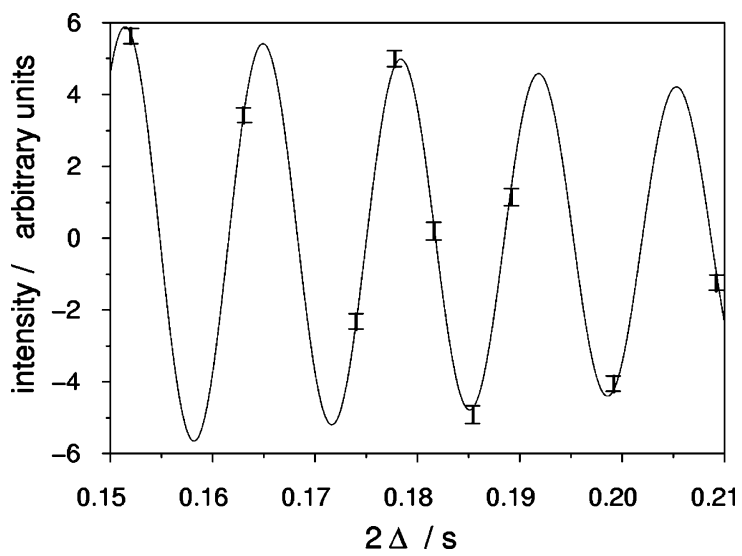

Figure 2. Typical NMR modulation curve due to the coupling ${ }^{1} K\left(\mathrm{C}_{5} \mathrm{H}_{5}\right)$ in the $N$-acetylglucosamine (GlcNAc) residue of the $\mathrm{Le}^{\mathrm{X}}$ molecule. The concentrations of $\mathrm{Le}^{\mathrm{X}}$ and calcium were 10 and $23 \mathrm{mM}$, dissolved in a partly oriented solution of $\mathrm{C}_{12} \mathrm{E}_{5} / \mathrm{h}$ solution at $50 \mathrm{~g} \cdot \mathrm{L}^{-1}$. The least-squares fit compares the 10 non-equidistant data points with the function $\exp \{-$ $\left.2 \Delta R_{2}\right\} \sin \left(\pi^{1} K_{\mathrm{CH}} 2 \Delta\right)$, where ${ }^{1} K_{\mathrm{CH}}={ }^{1} J_{\mathrm{CH}}+{ }^{1} D_{\mathrm{CH}}$ is the sum of scalar and dipolar couplings.

concentration, i.e., at 15,25 , and $35 \mathrm{mM}$ for 3-deoxygalactose-Le ${ }^{\mathrm{x}}$, at 11,18 , and $28 \mathrm{mM}$ for 4-deoxygalactose-Le $\mathrm{e}^{\mathrm{X}}$, and at 17,29 , and 35 $\mathrm{mM}$ for 6-deoxygalactose-Le ${ }^{\mathrm{x}}$. For the sake of comparison, we also measured the RDCs in $17 \mathrm{mM}$ methyl $\alpha$-D-galactopyranoside and in $17 \mathrm{mM}$ methyl $\alpha$-D-glucopyranoside, both with 0,21 , and $43 \mathrm{mM}$ $\mathrm{CaCl}_{2}$. The latter reference compounds were obtained from Acros Organic and Janssen Chimica.

NMR Spectroscopy. The sum of scalar $\left({ }^{1} J_{\mathrm{CH}}\right)$ and dipolar $\left({ }^{1} D_{\mathrm{CH}}\right)$ one-bond ${ }^{1} \mathrm{H}-{ }^{13} \mathrm{C}$ couplings, ${ }^{1} K_{\mathrm{CH}}={ }^{1} J_{\mathrm{CH}}+{ }^{1} D_{\mathrm{CH}}$, was measured using a two-dimensional (2D) $J$-modulation experiment described by Pham et al., ${ }^{27}$ which suppresses the effects of long-range couplings ${ }^{n} K_{\mathrm{CH}}$ and ${ }^{n} J_{\mathrm{CH}}(n>1)$ by a bilinear rotation decoupling (BIRD) sequence. ${ }^{31,32}$ The method was modified to include adiabatic ${ }^{13} \mathrm{C}$ refocusing RE-BURP pulses. ${ }^{33}$ The 2D spectra were acquired with different values of the delay $2 \Delta$ in the first INEPT step of the sequence (Figure S1, Supporting Information). Intensities of the ${ }^{13} \mathrm{C}-{ }^{1} \mathrm{H}$ correlation peaks were measured on each spectrum in order to sample the $\sin \left(\pi^{1} K_{\mathrm{CH}} 2 \Delta\right)$ modulation of the peak intensities on the $2 \mathrm{D}$ map. Reference spectra were acquired with $2 \Delta=3.24 \mathrm{~ms}$. The delay $2 \Delta$ was incremented in non-equidistant steps $(2 \Delta=152,163,194,177.8,181.6,185.4,189.2,199.2$, and 209.2 $\mathrm{ms})$. Sampling $2 \Delta$ over a few periods of the coupling modulation allowed unambiguous determination of ${ }^{1} K_{\mathrm{CH}}$, even in situations of low signal-to-noise. In order to gain resolution in the ${ }^{13} \mathrm{C}$ dimension while keeping reasonable acquisition times, the spectral widths in the indirect ${ }^{13} \mathrm{C}$ dimension were limited, so that the folded spectra appeared centered at $71.5 \mathrm{ppm}$. Each matrix consisted of $40 \times 512$ points in the ${ }^{13} \mathrm{C}$ and ${ }^{1} \mathrm{H}$ dimensions, with spectral widths of 1811 and $6010 \mathrm{~Hz}$. For a typical sample, 98 transients were acquired for each $t_{1}$ increment with a recycle delay of $1.5 \mathrm{~s}$. The overall acquisition time with a Bruker DRX 600 $\mathrm{MHz}$ spectrometer was $45 \mathrm{~h}$ for each series of 10 experiments. The data were processed with the NMRPipe software, ${ }^{34}$ and $2 \mathrm{D}$ peak intensities were estimated from Gaussian best-fits. The couplings ${ }^{1} K_{\mathrm{CH}}$ were obtained by a three-parameter $\left(I_{0}, R_{2},{ }^{1} K_{\mathrm{CH}}\right)$ least-squares fit, using Scilab software, ${ }^{35}$ of the experimental data to the expression $I=I_{0}$ $\exp \left(-2 \Delta R_{2}\right) \sin \left(\pi^{1} K_{\mathrm{CH}} 2 \Delta\right)$, where $R_{2}=1 / T_{2}\left({ }^{1} \mathrm{H}\right)$ is the transverse proton relaxation rate. A representative modulation curve is shown in Figure 2 .

(31) Garbow, J. R.; Weitekamp, D. P.; Pines, A. Chem. Phys. Lett. 1982, 93, 504.

(32) Uhrín, D.; Liptaj, T.; Kövér, K. E. J. Magn. Reson. Ser. A 1993, 101, 4146.

(33) Kupče, E.; Freeman, R. J. Magn. Reson. Ser. A 1995, 115, 273-276.

(34) Delaglio, F.; Grzesiek, S.; Vuister, G. W.; Zhu, G.; Pfeifer, J.; Bax, A. J. Biomol. NMR 1995, 6, 277-293.

(35) Scilab; INRIA: Rocquencourt, France, 1989-2005 (http://www.scilab.org) 


\section{Results and Discussion}

Spectra obtained in isotropic and oriented conditions did not differ in chemical shifts (see Figures S2-S5, Supporting Information). In addition, there were no changes in proton line widths, and the transverse relaxation rates $R_{2}\left({ }^{13} \mathrm{C}\right)$ measured by Carr-Purcell-Meiboom-Gill (CPMG) experiments were not significantly altered in 6-deoxy-galactose-Le ${ }^{\mathrm{X}}$ (see Table S6, Supporting Information).

The observed coupling ${ }^{1} K_{\mathrm{CH}}={ }^{1} D_{\mathrm{CH}}+{ }^{1} J_{\mathrm{CH}}$, as measured by the modulation experiments described above, is the sum of the residual dipolar and scalar couplings. Therefore, ${ }^{1} D_{\mathrm{CH}}={ }^{1} K_{\mathrm{CH}}$ $-{ }^{1} J_{\mathrm{CH}}$ can be obtained from the difference between the couplings observed under oriented and isotropic conditions.

Strong Coupling Effects. Since the BIRD pulse sequence is designed only for weakly coupled systems, strong coupling effects may lead to systematic errors. This problem has been investigated with numerical simulations by Pham et al. ${ }^{27}$

In a three-spin system $\left(\mathrm{C}_{i}, \mathrm{H}_{i}, \mathrm{H}_{j}\right)$, a measure of the coupling strength, determined by the degree of mixing between the unperturbed spin states, can be expressed by the parameter ${ }^{36}$ $\theta_{i j} \pm=(1 / 2) \arctan \left\{{ }^{3} K_{\mathrm{H}_{i} \mathrm{H}_{j}} /\left[\Delta \delta_{i j}-/+(1 / 2)\left({ }^{1} K_{\mathrm{C}_{i} \mathrm{H}_{i}}-{ }^{1} K_{\mathrm{C}_{j} \mathrm{H}_{j}}\right)\right]\right\}$, where $\Delta \delta_{i j}=\delta \mathrm{H}_{i}-\delta \mathrm{H}_{j}$ is the difference in proton chemical shifts. In this expression, $\theta_{i j} \pm$ relates to the $\mathrm{C}_{i}$ carbon spin in states $\alpha$ and $\beta$, respectively. However, the analysis of $J$-coupled three-spin systems in oligosaccharides shows that, depending on the sign of $\Delta \delta_{i j}$, strong coupling may arise for one of the carbon polarization states only, and a relevant measure of the degree of mixing ${ }^{27}$ is therefore represented by the parameter $\theta_{i j}=(1 / 2) \arctan \left\{{ }^{3} K_{\mathrm{H}_{i} \mathrm{H}_{j}} /\left[\left|\Delta \delta_{i j}\right|-(1 / 2)^{1} K_{\mathrm{C}_{i} \mathrm{H}_{i}}\right]\right\}$.

The BIRD sequence functions properly when the weak coupling approximation is applicable $\left(\theta_{i k} \leq 3^{\circ}\right)$. In this case, the measured coupling is not significantly affected by systematic errors. In a regime where $3^{\circ}<\theta_{i j} \leq 10^{\circ}$ (corresponding to $R$ $>3$ in the work of Pham et al.), ${ }^{27}$ systematic errors in the determination of ${ }^{1} K_{\mathrm{CH}}$ cancel out when comparing differences in the RDCs, ${ }^{1} D_{\mathrm{CH}}={ }^{1} K_{\mathrm{CH}}-{ }^{1} J_{\mathrm{CH}}$, observed in similar samples. Most subsystems in our samples fall into this category. Changes in ${ }^{1} K_{\mathrm{CH}}$ therefore indicate an actual change in the orientation of the saccharide. In the present study, experimental data were fitted using the weak coupling approximation. Data were fitted to this model with good confidence (statistical $Q$ values larger than $\left.10^{-3}\right) .{ }^{37}$ In situations where modulation experiments do not provide reliable measurements of absolute couplings, changes in apparent couplings can nevertheless be ascribed to changes in the RDCs.

If the protons are strongly coupled in the presence of ${ }^{13} \mathrm{C}$, the BIRD sequence should not be used to extract ${ }^{1} K_{\mathrm{CH}}$ couplings. In our case, the only strongly coupled system was $\left(\mathrm{C}_{5}, \mathrm{H}_{5}, \mathrm{H}_{6}\right)$ in the galactose residue of $\mathrm{Le}^{\mathrm{X}}$, which could therefore not be determined, in accordance with a low statistical $Q$ value of the fit.

Concentration Effects. At least two different complexes involving $\mathrm{Le}^{\mathrm{X}}$ and $\mathrm{Ca}^{2+}$ should be considered. In addition to the ternary $\mathrm{Le}^{\mathrm{X}}-\mathrm{Ca}^{2+}-\mathrm{Le}^{\mathrm{X}}$ complex with an affinity constant $K_{\mathrm{a}}^{\mathrm{tern}}$, which is believed to be of biological interest, one cannot

(36) Pople, J. A., Schneider, W. G., Bernstein, H. J. High Resolution Nuclear Magnetic Resonance; McGraw-Hill: New York, 1959.

(37) Press, W. H.; Flannery, B. P.; Teukolsky, S. A.; Vetterling, W. T. Numerical Recipes, The art of scientific computing (FORTRAN Version); Cambridge University Press: Cambridge, UK, 1989; pp 499-503. rule out the presence of binary $\mathrm{Le}^{\mathrm{X}}-\mathrm{Ca}^{2+}$ complexes with an affinity constant $K_{\mathrm{a}}^{\mathrm{bin}}$ :

$$
\begin{gathered}
2 \mathrm{Le}^{\mathrm{X}}+\mathrm{Ca}^{2+}=\mathrm{Le}^{\mathrm{X}}-\mathrm{Ca}^{2+}-\mathrm{Le}^{\mathrm{X}} \quad K_{\mathrm{a}}^{\mathrm{tern}} \\
\mathrm{Le}^{\mathrm{X}}+\mathrm{Ca}^{2+}=\mathrm{Le}^{\mathrm{X}}-\mathrm{Ca}^{2+} \quad K_{\mathrm{a}}^{\mathrm{bin}}
\end{gathered}
$$

Both of these complexes are expected to be very weak, so their concentrations in solution are negligible compared to those of the free species $\mathrm{Le}^{\mathrm{X}}$ and $\mathrm{Ca}^{2+}$. In particular, the concentration $\left[\mathrm{Le}^{\mathrm{X}}-\mathrm{Ca}^{2+}-\mathrm{Le}^{\mathrm{X}}\right]$ is expected to be very small, so the concentration of free $\mathrm{Le}^{\mathrm{X}}$ remains close to the total $\left[\mathrm{Le}^{\mathrm{X}}\right]_{\mathrm{T}}$ concentration. Under these conditions (see Supporting Information), the following equations apply:

$$
\begin{gathered}
{\left[\mathrm{Le}^{\mathrm{X}}-\mathrm{Ca}^{2+}-\mathrm{Le}^{\mathrm{X}}\right] /\left[\mathrm{Le}^{\mathrm{X}}\right]_{\mathrm{T}} \approx K_{\mathrm{a}}^{\mathrm{tern}}\left[\mathrm{Le}^{\mathrm{X}}\right]_{\mathrm{T}}\left[\mathrm{Ca}^{2+}\right]_{\mathrm{T}}} \\
{\left[\mathrm{Le}^{\mathrm{X}}-\mathrm{Ca}^{2+}\right] /\left[\mathrm{Le}^{\mathrm{X}}\right]_{\mathrm{T}} \approx K_{\mathrm{a}}^{\mathrm{bin}}\left[\mathrm{Ca}^{2+}\right]_{\mathrm{T}}}
\end{gathered}
$$

where $\left[\mathrm{Ca}^{2+}\right]_{\mathrm{T}}$ is the total concentration of $\mathrm{Ca}^{2+}$ in the solution. Small deviations from linearity are expected for non-negligible $\left[\mathrm{Le}^{\mathrm{X}}-\mathrm{Ca}^{2+}-\mathrm{Le}^{\mathrm{X}}\right] /\left[\mathrm{Le}^{\mathrm{X}}\right]_{\mathrm{T}}$ ratios. Since the NMR spectra of the $\mathrm{Le}^{\mathrm{X}}$ show a single peak for each carbon-13, the exchange between free and bound $\mathrm{Le}^{\mathrm{X}}$ can be assumed to be in the fast exchange limit, and the experimental residual dipolar coupling ${ }^{1} D_{\mathrm{CH}}^{\mathrm{exp}}$ therefore represents the weighted average between the free and complexed oligosaccharides:

$$
\begin{aligned}
{ }^{1} D_{\mathrm{CH}}^{\mathrm{exp}}=\left[\mathrm{Le}^{\mathrm{X}}\right] /\left[\mathrm{Le}^{\mathrm{X}}\right]_{\mathrm{T}}{ }^{1} D_{\mathrm{CH}}^{\text {free }}+\left[\mathrm{Le}^{\mathrm{X}}-\mathrm{Ca}^{2+}-\mathrm{Le}^{\mathrm{X}}\right] / \\
{\left[\mathrm{Le}^{\mathrm{X}}\right]_{\mathrm{T}}{ }^{1} D_{\mathrm{CH}}^{\text {tern }}+\left[\mathrm{Le}^{\mathrm{X}}-\mathrm{Ca}^{2+}\right] /\left[\mathrm{Le}^{\mathrm{X}}\right]_{\mathrm{T}}{ }^{1} D_{\mathrm{CH}}^{\mathrm{bin}} }
\end{aligned}
$$

where ${ }^{1} D_{\mathrm{CH}}^{\text {tern }}$ and ${ }^{1} D_{\mathrm{CH}}^{\text {bin }}$ are the RDCs of the ternary and binary complexes. Mass conservation leads to

$$
\begin{array}{r}
{\left[\mathrm{Le}^{\mathrm{X}}\right] /\left[\mathrm{Le}^{\mathrm{X}}\right]_{\mathrm{T}}=1-\left[\mathrm{Le}^{\mathrm{X}}-\mathrm{Ca}^{2+}-\mathrm{Le}^{\mathrm{X}}\right] /\left[\mathrm{Le}^{\mathrm{X}}\right]_{\mathrm{T}}-} \\
{\left[\mathrm{Le}^{\mathrm{X}}-\mathrm{Ca}^{2+}\right] /\left[\mathrm{Le}^{\mathrm{X}}\right]_{\mathrm{T}}}
\end{array}
$$

Combining eqs 3-6 leads to

$$
\begin{array}{r}
{ }^{1} D_{\mathrm{CH}}^{\mathrm{exp}}={ }^{1} D_{\mathrm{CH}}^{\mathrm{free}}+2 K_{\mathrm{a}}^{\mathrm{tern}}\left[\mathrm{Ca}^{2+}\right]_{\mathrm{T}}\left[\mathrm{Le}^{\mathrm{X}}\right]_{\mathrm{T}}\left({ }^{1} D_{\mathrm{CH}}^{\mathrm{tern}}-{ }^{1} D_{\mathrm{CH}}^{\mathrm{free}}\right)+ \\
K_{\mathrm{a}}^{\mathrm{bin}}\left[\mathrm{Ca}^{2+}\right]_{\mathrm{T}}\left({ }^{1} D_{\mathrm{CH}}^{\mathrm{bin}}-{ }^{1} D_{\mathrm{CH}}^{\text {free }}\right)
\end{array}
$$

The experimental couplings ${ }^{1} D_{\mathrm{CH}}^{\mathrm{exp}}$ should therefore depend on the concentrations $\left[\mathrm{Ca}^{2+}\right]_{\mathrm{T}}$ and $\left[\mathrm{Le}^{\mathrm{X}}\right]_{\mathrm{T}}$. However, the second term on the right-hand side of eq 7 is related to the formation of the ternary complex $\mathrm{Le}^{\mathrm{X}}-\mathrm{Ca}^{2+}-\mathrm{Le}^{\mathrm{X}}$ and has a linear dependence on $\left[\mathrm{Le}^{\mathrm{X}}\right]_{\mathrm{T}}$, characterized by the slope 2 $K_{\mathrm{a}}^{\mathrm{tern}}\left[\mathrm{Ca}^{2+}\right]_{\mathrm{T}}\left({ }^{1} D_{\mathrm{CH}}^{\mathrm{tern}}-{ }^{1} D_{\mathrm{CH}}^{\mathrm{free}}\right)$. Clearly, this slope depends on the association constant $K_{\mathrm{a}}^{\mathrm{tern}}$, on the structure of the complex, and on its orientation tensor. The existence of higher-order complexes of the type $\mathrm{Le}_{n}{ }_{n}-\mathrm{Ca}^{2+}{ }_{k}$ was also considered. Their presence would lead to deviations from the linear dependence behavior (see Supporting Information). Unfortunately, the association constants remain too weak to be quantified by solution-state NMR. It appears too bold to combine our observations with estimates of association constants obtained under dramatically different conditions. ${ }^{13,20}$ Thus, the variations of RDCs reported in this work are to be regarded merely as qualitative indicators of complex formation. These measurements provide a unique way of detecting $\mathrm{Le}^{\mathrm{X}} / \mathrm{Le}^{\mathrm{X}}$ interactions and the presence of the $\mathrm{Le}^{\mathrm{X}}-\mathrm{Ca}^{2+}-\mathrm{Le}^{\mathrm{X}}$ complexes in solution. 


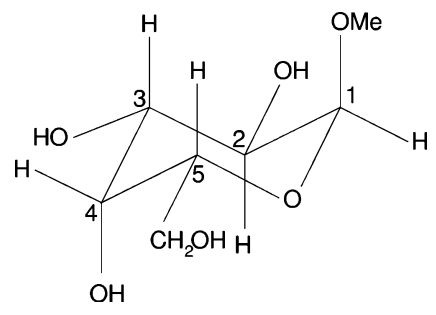

Figure 3. Methyl $\alpha$-D-galactopyranoside.

Table 1. Measurements of Residual Dipolar Couplings ${ }^{1} D_{\mathrm{CH}}$ for the Vectors $\mathrm{C}_{i} \mathrm{H}_{i}$ in Methyl $\alpha$-D-Galactopyranoside in $\mathrm{C}_{12} \mathrm{E}_{5} / \mathrm{h}$

\begin{tabular}{ccccc}
\hline & $\mathrm{C}_{1} \mathrm{H}_{1}$ & $\mathrm{C}_{2} \mathrm{H}_{2}$ & $\mathrm{C}_{3} \mathrm{H}_{3}$ & $\mathrm{C}_{4} \mathrm{H}_{4}$ \\
\hline${ }^{1} D_{\mathrm{CH}}{ }^{a}$ & $+3.58 \pm 0.04$ & $+3.45 \pm 0.05$ & $+3.69 \pm 0.06$ & $+3.39 \pm 0.04$ \\
slope $^{b}$ & $-4.4 \pm 0.7$ & $-7.2 \pm 0.8$ & $-10 \pm 1$ & $-4.9 \pm 0.7$ \\
\hline
\end{tabular}

${ }^{a}$ Couplings ${ }^{1} D_{\mathrm{CH}}$ in the absence of calcium chloride, in $\mathrm{Hz} .{ }^{b}$ The derivative of the variations of ${ }^{1} D_{\mathrm{CH}}$ as a function of $\mathrm{CaCl}_{2}$ concentration, in $\mathrm{Hz} \cdot \mathrm{M}^{-1}$.

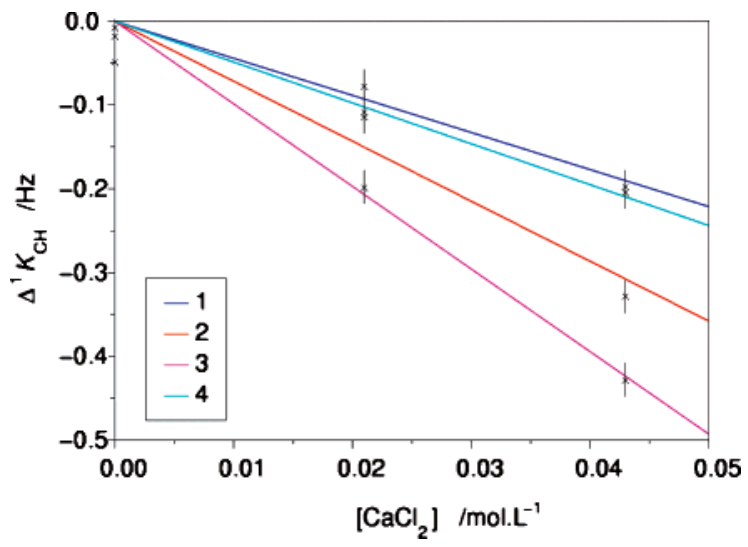

Figure 4. Variations of the couplings $\Delta^{1} K_{\mathrm{CH}}$ of four $\mathrm{C}_{i} \mathrm{H}_{i}$ pairs with $i=$ $1,2,3$, or 4 in methyl $\alpha$-D-galactopyranoside in $\mathrm{C}_{12} \mathrm{E}_{5} / \mathrm{h}$ as a function of the $\mathrm{CaCl}_{2}$ concentration.

Control Experiments. A series of experiments were performed on methyl $\alpha$-D-galactopyranoside (Figure 3 ) in the same medium as used for the $\mathrm{Le}^{\mathrm{X}}$ study, in order to assess whether calcium chloride has any effects on the orienting properties of the $\mathrm{C}_{12} \mathrm{E}_{5} / \mathrm{h}$ medium. Since methyl $\alpha$-D-galactopyranoside is known from calorimetry not to interact with $\mathrm{Ca}^{2+}$ ions, ${ }^{38}$ it can be used as a reference. The couplings ${ }^{1} K_{\mathrm{CH}}$ were measured for the $\mathrm{C}_{1} \mathrm{H}_{1}, \mathrm{C}_{2} \mathrm{H}_{2}, \mathrm{C}_{3} \mathrm{H}_{3}$, and $\mathrm{C}_{4} \mathrm{H}_{4}$ pairs of nuclei (Table 1). No coupling could be obtained for the $\mathrm{C}_{5} \mathrm{H}_{5}$ pair because of strong coupling effects. The comparison between the couplings obtained in isotropic and weakly orienting conditions indicates that methyl $\alpha$-D-galactopyranoside in $\mathrm{C}_{12} \mathrm{E}_{5} / \mathrm{h}$ is partially oriented: non-vanishing ${ }^{1} D_{\mathrm{CH}}$ couplings were measured for each of the four neighboring ${ }^{13} \mathrm{C}^{-1} \mathrm{H}$ pairs (see Table 1 ).

Addition of 21 or $43 \mathrm{mM} \mathrm{CaCl} 2$ had no effect on either resonance frequencies or line widths in the ${ }^{1} \mathrm{H}-{ }^{13} \mathrm{C}$ spectrum of methyl $\alpha$-D-galactopyranoside. No modification of the residual deuterium quadrupolar splitting, $\omega_{\mathrm{Q}}$, of $\mathrm{D}_{2} \mathrm{O}$ was observed. However, the RDCs ${ }^{1} D_{\mathrm{CH}}$ of the four neighboring ${ }^{13} \mathrm{C}-{ }^{1} \mathrm{H}$ pairs vary in proportion to the concentration of $\mathrm{CaCl}_{2}$ (Figure 4 and Table 1).

The dependence of ${ }^{1} D_{\mathrm{CH}}$ in methyl $\alpha$-D-galactopyranoside on the concentration of $\mathrm{CaCl}_{2}$ (Figure 4) could be explained

(38) Morel-Desrosiers, N.; Morel, J.-P. J. Chem. Soc., Faraday Trans. 11985 , $10,3461-3469$

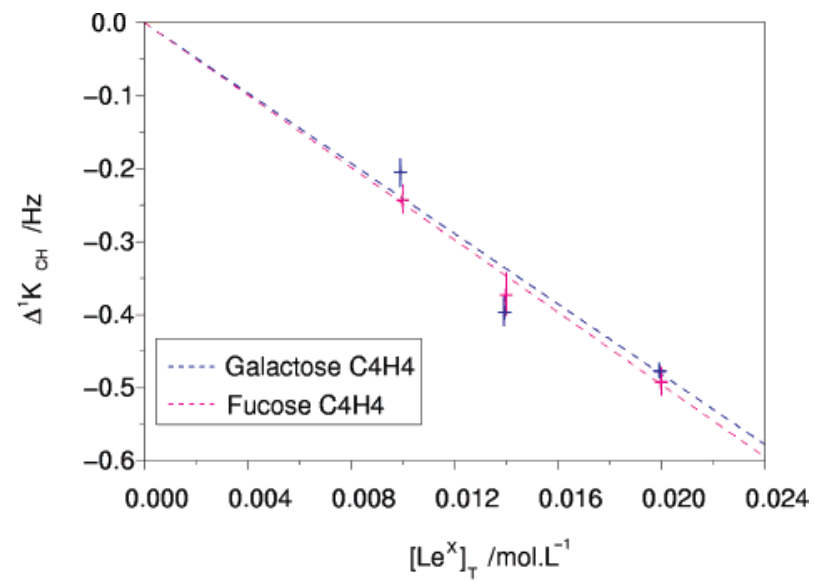

Figure 5. Variations of the couplings $\Delta^{1} K_{\mathrm{CH}}$ as a function of the concentration $\left[\mathrm{Le}^{\mathrm{X}}\right]_{\mathrm{T}}$ for the equatorial $\mathrm{C}_{4} \mathrm{H}_{4}$ vectors of the galactose and fucose residues of $\mathrm{Le}^{\mathrm{X}}$.

Table 2. Derivative of the Change in RDCs, $\Delta^{1} K_{\mathrm{CH}}$, as a Function of [Saccharide] (in $\mathrm{Hz} \cdot \mathrm{mol}^{-1} \cdot \mathrm{L}$ ), Measured for Various Vectors $\mathrm{C}_{i} \mathrm{H}_{i}$ in the Three Saccharide Units of $\mathrm{Le}^{\mathrm{X}}$ in $\mathrm{C}_{12} \mathrm{E}_{5} / \mathrm{h}$ with $23 \mathrm{mM}$ $\mathrm{CaCl}_{2}$

\begin{tabular}{|c|c|c|c|c|}
\hline vector $\mathrm{C}_{i} \mathrm{H}_{i}$ & $\operatorname{Le}^{x}$ & $\begin{array}{l}\text { 3-deoxy- } \\
\text { Gal-Le }\end{array}$ & $\begin{array}{l}\text { 4-deoxy- } \\
\text { Gal-Le }\end{array}$ & $\begin{array}{l}\text { 6-deoxy- } \\
\text { Gal-Le }\end{array}$ \\
\hline$\omega_{\mathrm{Q}}\left(\mathrm{D}_{2} \mathrm{O}\right)^{a}$ & $34 \pm 2$ & 35.1 & 47.4 & 42.8 \\
\hline GlcNAc 1 & & $+4 \pm 2$ & $-38 \pm 5$ & $+4 \pm 6$ \\
\hline GlcNAc 2 & $-20 \pm 8$ & $+3 \pm 2$ & $+12 \pm 6$ & $+11 \pm 6$ \\
\hline GlcNAc 3 & $-7 \pm 7$ & $+14 \pm 2$ & $+22 \pm 4$ & $+7 \pm 2$ \\
\hline GlcNAc 4 & $+5 \pm 10$ & $+7 \pm 2$ & $+21 \pm 3$ & $+11 \pm 3$ \\
\hline GlcNAc 5 & $+30 \pm 5$ & $+1 \pm 2$ & $+20 \pm 3$ & $+12 \pm 4$ \\
\hline Gal 1 & & $-4 \pm 2$ & $0 \pm 3$ & $+11 \pm 4$ \\
\hline Gal 2 & $-10 \pm 5$ & $0 \pm 2$ & $+4 \pm 2$ & $+15 \pm 2$ \\
\hline Gal 3 & $-4 \pm 3$ & & $+15 \pm 2$ & $-12 \pm 3$ \\
\hline Gal 4 & $-24 \pm 2$ & $-6 \pm 2$ & & $-14 \pm 2$ \\
\hline Fuc 1 & $+4 \pm 13$ & $-11 \pm 1$ & $-4 \pm 2$ & $0 \pm 2$ \\
\hline Fuc 2 & $+23 \pm 5$ & $+1 \pm 1$ & $+6 \pm 2$ & $-5 \pm 2$ \\
\hline Fuc 3 & $+8 \pm 4$ & $+6 \pm 2$ & $+3 \pm 2$ & $+13 \pm 2$ \\
\hline Fuc 4 & $-25 \pm 3$ & $+5 \pm 2$ & $-4 \pm 2$ & $-12 \pm 2$ \\
\hline Fuc 5 & $-11 \pm 11$ & $+7 \pm 1$ & $+9 \pm 3$ & $0 \pm 5$ \\
\hline
\end{tabular}

${ }^{a}$ Residual quadrupolar splitting of deuterium in $\mathrm{D}_{2} \mathrm{O}$, in $\mathrm{Hz}$.

either by direct interactions between calcium ions and the saccharide or by interactions between calcium ions and the partly oriented $\mathrm{C}_{12} \mathrm{E}_{5} / \mathrm{h}$ medium, which would then affect the orientation of the saccharide indirectly. Direct interactions appear unlikely for this monosaccharide (in contrast to $\mathrm{Le}^{\mathrm{X}}$ ), while indirect interference appears plausible, since both $\mathrm{C}_{12} \mathrm{E}_{5}$ and $n$-hexanol contain oxygen atoms that can weakly bind to cations. A similar study of ${ }^{1} D_{\mathrm{CH}}$ in another monosaccharide used as a reference compound, methyl $\alpha$-D-glucopyranoside, showed effects nearly identical to those shown in Figure 4 (see Table S1, Supporting Information). We conclude that direct interactions between calcium ions and the two monosaccharides can be neglected, and that the calcium ions modify the orientation indirectly by acting on the $\mathrm{C}_{12} \mathrm{E}_{5} / \mathrm{h}$ medium. Note that the mere variations of $\mathrm{RDCs}$ upon addition of $\mathrm{CaCl}_{2}$ should definitely $n o t$ be used as criteria for direct interactions between ions and $\mathrm{Le}^{\mathrm{X}}$-related molecules.

In contrast, variation of methyl $\alpha$-D-glucopyranoside concentration has no effect on its RDCs, as there is no variation of ${ }^{1} K_{\mathrm{CH}}$ (see Table S1, Supporting Information). The $\mathrm{C}_{12} \mathrm{E}_{5} / \mathrm{h}$ medium properties are not modified when the saccharide concentration changes. 

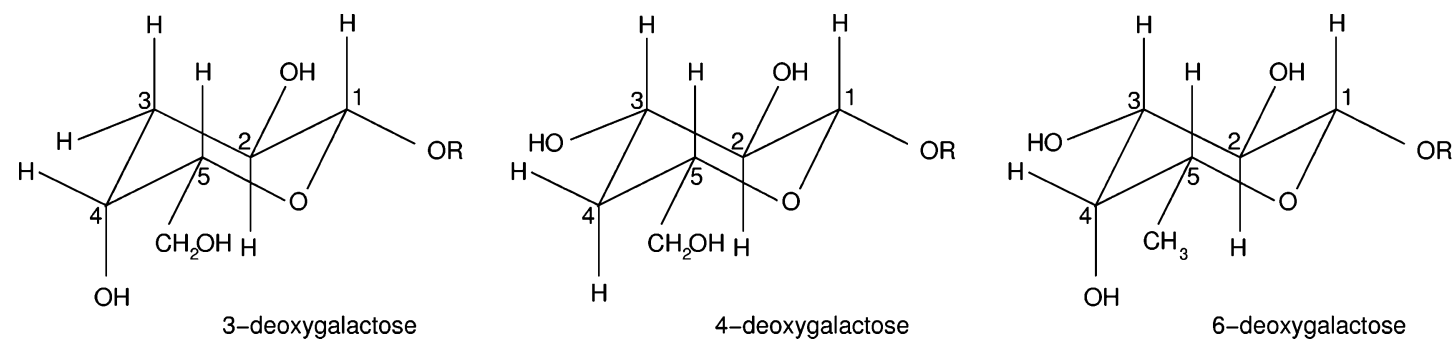

Figure 6. Synthetic deoxy forms of galactose residues in 3-deoxygalactose-Le ${ }^{\mathrm{X}}$, 4-deoxygalactose-Le ${ }^{\mathrm{X}}$, and 6-deoxygalactose-Le ${ }^{\mathrm{X}}$.

Effect of Le $^{\mathrm{X}}$ Concentration. The mere fact that the total couplings ${ }^{1} K_{\mathrm{CH}}$ observed in the $\mathrm{Le}^{\mathrm{X}}$ trisaccharide in the oriented phase differ from the ${ }^{1} J_{\mathrm{CH}}$ couplings measured in isotropic solution is an indication that $\mathrm{Le}^{\mathrm{X}}$ is oriented by the $\mathrm{C}_{12} \mathrm{E}_{5} / \mathrm{h}$ medium. Significant residual dipolar couplings ${ }^{1} D_{\mathrm{CH}}$ were obtained, with values between $7.09 \pm 0.17$ and $-2.74 \pm 0.07$ $\mathrm{Hz}$ (see Table S2, Supporting Information). Interestingly, the RDCs observed for $\mathrm{C}_{2} \mathrm{H}_{2}, \mathrm{C}_{3} \mathrm{H}_{3}$, and $\mathrm{C}_{4} \mathrm{H}_{4}$ in the glucosamine residue have the same sign and are ca. 3 times larger than the other RDCs in $\mathrm{Le}^{\mathrm{X}}$. This suggests that these three nearly parallel vectors may be aligned in a direction that is close to the largest component of the alignment tensor. Upon addition of $\mathrm{CaCl}_{2}$, we observed changes $\Delta^{1} K_{\mathrm{CH}}$ ranging from $+0.89 \pm 0.04$ to $-0.47 \pm 0.07 \mathrm{~Hz}$ (see Table S3, Supporting Information), but there was no significant effect on either chemical shifts or line widths in the ${ }^{1} \mathrm{H}-{ }^{13} \mathrm{C}$ spectra. However, as discussed above, $\mathrm{Ca}^{2+}$ clearly interacts with the orienting medium, thus entailing changes in the observed couplings. Therefore, $\Delta^{1} K_{\mathrm{CH}}$ changes upon $\mathrm{Ca}^{2+}$ titration should not be interpreted as evidence of direct $\mathrm{Le}^{\mathrm{X}} / \mathrm{Ca}^{2+}$ interactions, since they can be, at least in part, caused indirectly by the effect of calcium ions on the orienting properties of the $\mathrm{C}_{12} \mathrm{E}_{5} / \mathrm{h}$ phase.

In contrast, the orientation of the $\mathrm{Le}^{\mathrm{X}}$ in the orienting $\mathrm{C}_{12} \mathrm{E}_{5} / \mathrm{h}$ medium is not expected to be sensitive to its concentration. Therefore, the observation of variations $\Delta^{1} K_{\mathrm{CH}}$ upon increasing the $\mathrm{Le}^{\mathrm{X}}$ concentration can be readily ascribed to the formation of a ternary complex $\mathrm{Le}^{\mathrm{X}}-\mathrm{Ca}^{2+}-\mathrm{Le}^{\mathrm{X}}$. The ${ }^{1} K_{\mathrm{CH}}$ couplings were measured at three different $\mathrm{Le}^{\mathrm{X}}$ concentrations, all in the presence of $23 \mathrm{mM} \mathrm{CaCl}$. While peak widths and positions remained constant, significant variations $\Delta^{1} K_{\mathrm{CH}}$ were observed (Figure 5). Due to the presence of axial and equatorial $\mathrm{CH}$ bonds with different relative orientations, the ${ }^{1} K_{\mathrm{CH}}$ couplings exhibit different variations upon $\mathrm{Le}^{\mathrm{X}}$ titration. The derivative of the variations $\Delta^{1} K_{\mathrm{CH}}$ with respect to the concentration [Le ${ }^{\mathrm{X}}$ ], i.e., $2 K_{\mathrm{a}}^{\text {tern }}\left[\mathrm{Ca}^{2+}\right]\left({ }^{1} D_{\mathrm{CH}}^{\text {tern }}-{ }^{1} D_{\mathrm{CH}}^{\text {free }}\right)$ (see eq 6 ), were determined for several $\mathrm{C}_{i} \mathrm{H}_{i}$ vectors in the three saccharide residues of $\mathrm{Le}^{\mathrm{X}}$ (see Table 2). The variations $\Delta^{1} K_{\mathrm{CH}}$ must reflect changes in the average orientation of the corresponding $\mathrm{C}_{i} \mathrm{H}_{i}$ vectors and therefore indicate the presence of $\mathrm{Le}^{\mathrm{X}}-\mathrm{Ca}^{2+}-\mathrm{Le}^{\mathrm{X}}$ complexes in solution.

Trisaccharides Chemically Derived from $\mathbf{L e}^{\mathbf{X}}$. In order to gain more insight into the interactions involved in the formation of the ternary $\mathrm{Le}^{\mathrm{X}}-\mathrm{Ca}^{2+}-\mathrm{Le}^{\mathrm{X}}$ complex, we investigated various closely related molecules obtained by chemical modifications of the galactose residue of $\mathrm{Le}^{\mathrm{X}}$. To this aim, three molecules derived from $\mathrm{Le}^{\mathrm{X}}$, in which one of the hydroxyl group of galactose residue is replaced by a hydrogen atom, were synthesized, ${ }^{29,30}$ respectively leading to 3-deoxygalactose-Le ${ }^{\mathrm{X}}$, 4-deoxygalactose-Le ${ }^{\mathrm{X}}$, and 6-deoxygalactose-Le ${ }^{\mathrm{X}}$ (Figure 6). In order to determine their ability to form complexes in the

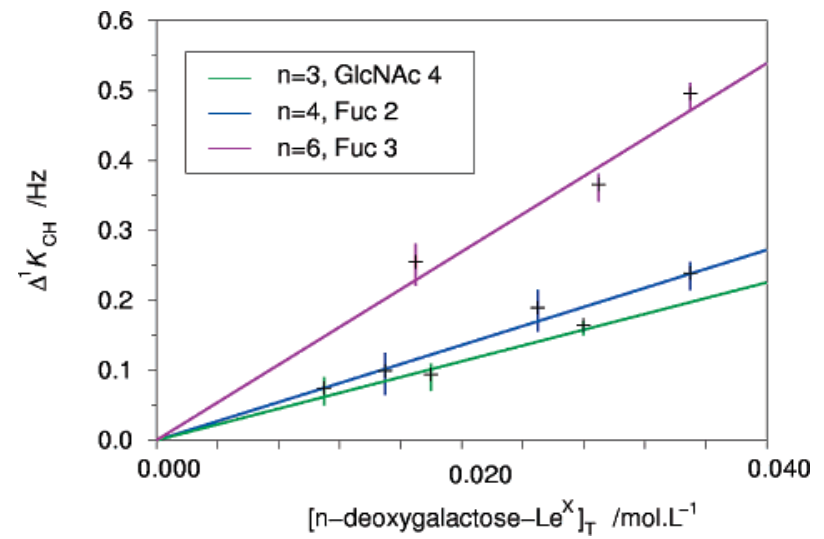

Figure 7. Variation of coupling $\Delta^{1} K_{\mathrm{CH}}$ as a function of the concentration [n-deoxygalactose-Le $\left.{ }^{\mathrm{X}}\right]_{\mathrm{T}}$ for typical $\mathrm{C}_{i} \mathrm{H}_{i}$ vectors in one of the sugar residues.

presence of calcium ions, and thus better understand the possible role played by the substituted hydroxyl groups in the complex formation, the three saccharides were studied using the same experimental protocol.

All deoxygalactose- $\mathrm{Le}^{\mathrm{X}}$ trisacharides were found to orient in $\mathrm{C}_{12} \mathrm{E}_{5} / \mathrm{h}$ and give rise to non-vanishing residual dipolar couplings ${ }^{1} D_{\mathrm{CH}}$ (see Table S4, Supporting Information). As in the case of $\mathrm{Le}^{\mathrm{X}}$, no spectral modifications (chemical shifts or peak widths) were observed upon addition of calcium chloride. For each of the three cases, measurements were performed at three deoxygalactose- $\mathrm{Le}^{\mathrm{X}}$ concentrations. As explained above, the measured values of the couplings should not be compared between the samples, owing to slight differences in the $\mathrm{C}_{12} \mathrm{E}_{5} / \mathrm{h}$ mixtures, which are likely to result in different orienting properties. The corresponding derivatives of $\Delta^{1} K_{\mathrm{CH}}$ are reported in Table 2. The variations are significant compared to the experimental errors (see also Figure 7). Therefore, these experiments unambiguously demonstrate the ability of 3-deoxygalactose-Le ${ }^{X}, 4$-deoxygalactose-Le ${ }^{X}$, and 6-deoxygalactose-Le ${ }^{X}$ to form ternary complexes in the presence of calcium ions, just like the native $\mathrm{Le}^{\mathrm{X}}$. Interestingly, none of the three hydroxy groups in positions 3,4 , and 6 on the galactose residue by itself was shown to be essential for carbohydrate/calcium/carbohydrate interactions. It is well known that interactions between calcium and sugars are complicated processes in which many atoms are involved, and the data presented in this study are consistent with the fact that calcium ions may accept different geometries of their coordination sphere. ${ }^{39,40}$

\section{Conclusions}

In this article, we have presented NMR methods that allow one to detect the formation of weak complexes with affinities

(39) Bugg, C. E. J. Am. Chem. Soc. 1973, 95, 908-913.

(40) Gyurcsik, B.; Nagy, L. Coord. Chem. Rev. 2000, 203, 81-149. 
that are too low to give rise to any variations of chemical shifts or line widths. It is possible to demonstrate the existence of such complexes by measuring the variation of residual dipolar couplings as a function of the concentration of the monomer. We applied this approach to the case of the trisaccharide $\mathrm{Le}^{\mathrm{X}}$ in a partly oriented solution. Thus, the variation of the measured residual dipolar couplings, ${ }^{1} D_{\mathrm{CH}}$, of various $\mathrm{C}_{i} \mathrm{H}_{i}$ vectors in the saccharide residues at increasing concentrations of $\mathrm{Le}^{\mathrm{X}}$ clearly demonstrated the existence of ternary $\mathrm{Le}^{\mathrm{X}}-\mathrm{Ca}^{2+}-\mathrm{Le}^{\mathrm{X}}$ complexes in solution. In addition, synthetic 3-, 4-, and 6-deoxy$\mathrm{Le}^{\mathrm{X}}$ variants were also shown to form complexes in the presence of calcium ions, despite the replacement of one of their hydroxy groups by a hydrogen atom. Our results thereby complement previous knowledge obtained in studies performed on $\mathrm{Le}^{\mathrm{X}} 11,12$ or other related oligosaccharides ${ }^{41,42}$ under very different experimental conditions. To the authors' knowledge, this is the

(41) Martin-Pastor, M.; Canales, A.; Corzana, F.; Asensio, J. L.; JimenezBarbero, J. J. Am. Chem. Soc. 2005, 127, 3589-3595.

(42) Haseley, S. R.; Vermeer, H. J.; Kamerling, J. P.; Vliegenhart, J. F. G. Proc Natl. Acad. Sci. U.S.A. 2001, 98, 9419-9424. first direct observation of the calcium-mediated interaction between such low-molecular-weight compounds in solution. Finally, our method offers an elegant and robust way to identify very weak complexes. It can, in principle, be generalized to any pair of weakly interacting molecules in solution.

Acknowledgment. This work is dedicated to Professor Pierre Sinay. It has been supported by the European Union (Research Training Network "Cross-Correlations" HPRN-CT-2000-00092, Coordination Action "Focusing NMR on the machinery of life", Integrated Infrastructure Initiative "EU-NMR"), the Université Paris VI, the Ministère de l'Education Nationale, de la Recherche et de la Technologie (MENRT), and the Centre National de la Recherche Scientifique (CNRS), France.

Supporting Information Available: Tables S1-S6, Figures $\mathrm{S} 1-\mathrm{S} 5$, and additional calculations for bimolecular and higher complexes. This material is available free of charge via the Internet at http:// pubs.acs.org.

JA0711056 